\title{
Identification of Glioma Stem Cells: What is Already Known and How Far do We Still Need to Go? The Biomarkers Dilemma
}

\author{
Paola Brescia\#, Cristina Richichi\#, and Giuliana Pelicci*
}

Department of Experimental Oncology, European Institute of Oncology (IEO), Milan, Italy

"Equally Contributed

\begin{abstract}
Cancer stem cells (CSCs) have been isolated in multiple tumour types and although the presence of surface markers selectively expressed on CSCs can be used to isolate these cells, no marker or pattern of markers are sufficiently robust to definitively identify CSCs.

Several markers have been evaluated for their prognostic value with promising early results, however to date none has been proven to be clinically useful in large-scale studies. A major need exists to identify markers of CSCs for glioblastoma (GBM), which would yield new therapeutic interventions. Given the complex genetic and epigenetic heterogeneity of human GBMs, it is unlikely that the expression of a single marker will define CSCs in every tumour, hence a combination of markers will probably best define glioma tumour stem cells.

The studies reported in the literature regarding the identification of specific cell surface markers involved in tumourigenic processes of the GBM tumour-initiating cells have been inconclusive. Further investigations are necessary to identify both CSC-specific markers and the molecular mechanism sustaining the tumourigenic potential of these cells in order to develop novel treatments to target this group of cells. Markers for GBM stem cells such as CD133, CD15, integrin a6, L1CAM, are available and might be informative to identify these cells but cannot be conclusively linked to a stem cell phenotype. Overlap of expression, functional state and morphology of different subpopulations lead us to reconsider, or carefully consider, the techniques employed so far to characterize cancer stem cells. Major effort might be exploited to look for alternative methods, to isolate CSCs independently from markers. Due to a dearth of methods and markers that reliably assay the function of candidate stem cells, the isolation/enrichment of tumoural stem cells to be therapeutically targeted remains a major challenge.
\end{abstract}

\section{Introduction}

The cancer stem cell hypothesis postulates that a small subpopulation of cancer cells possessing self-renewal characteristics is responsible for initiating and maintaining cancer growth. According to the CSC model the large populations found in a tumour might represent diverse stages of differentiation. The biological characteristics shared by normal stem cells (NSCs) and CSCs mainly involve selfrenewal and differentiation potential, survival ability, niche-specific microenvironment requirements and specific homing to injury sites and may have important implications in terms of new approaches to cancer. The identification of new therapeutic targets based on the CSC model represents a great challenge.

Glioblastoma multiforme (WHO grade IV) is the most aggressive among the brain tumours of adults and displays striking morphologic variation among different patients. GBM contains mixture cell populations with high propensity to infiltrate throughout the brain (making complete surgical resection impossible). It has been demonstrated that the bulk of malignant cells in GBM is generated by rare fractions of self-renewing, multipotent tumour initiating cells (CSCs) also called tumour-initiating cells or tumour-propagating cells $[1,2]$ responsible for tumour growth and recurrence and resistance to chemo- and radiotherapies [3].

Cancer stem cells generate tumours with the cardinal features of the GBMs from which they derived, including an infiltrative phenotype and histopathological features such as hypercellularity, pseudopalisading necrosis and angiogenesis. With the available tools it is difficult to isolate such cells directly from biopsies since the bias derived from the heterogeneity of the cellular composition of the specimen will not give reliable and precise results. The approach of processing and isolating the glioma stem cells from the original tumour gives rise to inconsistencies among various groups since it is not yet clear how stable is the phenotype of the glioma stem cell.

Although in some tumours, such as breast, prostate, pancreas, skin, colon and blood cancer, the presence of a slowly cycling and highly tumourigenic cell fraction is recognized [4-9,10-12], no single antigen has been shown to reliably segregate tumourigenic stem cells from the rest of the tumour specimen. The identification of tumoural neural stem cells will provide a powerful tool to investigate the tumourigenic process in the central nervous system and to develop therapies targeted to these cells. This takes on additional importance in the light of the demonstration that aberrant and multiple states of differentiation may be present within the same tumour. To date, current techniques have neither isolated nor defined profiles absolutely representative of a stem cell.

Although several markers may be informative towards brain tumour stem cell identification, the segregation of universal, specific

*Corresponding author: Giuliana Pelicci, Department of Experimental Oncology, European Institute of Oncology (IEO), Milan, Italy, Tel: +390257489830; Fax: +390294375990; E-mail: giuliana.pelicci@ifom-ieo-campus.it

Received July 05, 2011; Accepted August 04, 2011; Published August 08, 2011

Citation: Brescia P, Richichi C, Pelicci G (2011) Identification of Glioma Stem Cells: What is Already Known and How Far do We Still Need to Go? The Biomarkers Dilemma. J Carcinogene Mutagene S1:003. doi:10.4172/2157-2518.S1-003

Copyright: ( 2011 Brescia P, et al. This is an open-access article distributed unde the terms of the Creative Commons Attribution License, which permits unrestricted use, distribution, and reproduction in any medium, provided the original author and source are credited. 
markers that might be reliably used to distinguish a normal stem cell from a cancer stem cell as well as a stem cell from a progenitor is still inadequate.

There is an overall lack of standardization regarding methods for cell sorting and assessment of "stemness" confirmation. Moreover, there is a highly relevant debate regarding the best method for culturing the glioma stem cells isolated from human specimens: many groups proposed the use of adherent monolayer cultures rather than non-adherent cultures, since an homogeneous exposure to growth factors, oxygen and nutrients increases the possibility of obtaining a more homogeneous cell population [13,14]. On the other hand, the sphere forming assay has been used by many laboratories as "the assay" to retrospectively isolate stem cells from GBMs [15,16] although its reliability and benefits are still under debate. It has been reported that under appropriate conditions cultured tumour stem cells derived from primary human glioblastomas exhibit genotype, gene expression profile and biology of their parental primary tumours [17].

Neural stem cells were originally characterized and identified by their growth as neurospheres in a minimal medium containing growth factors $[15,16]$ and there is a considerable body of evidence linking the ability ofbrain tumours to give rise to multipassaged neurosphere cultures ex-vivo with patient clinical outcome [18].

This review aims to approach the CSC hypothesis to tackle the main challenge of this decade: the identification of reliable markers to defeat gliomas.

\section{How powerful is CD133 as a CSCs marker in brain tumours?}

CD133 is considered a marker of stem cells in diverse normal tissues and cancer types. Several studies demonstrated the utility of CD133 in the enrichment of populations of cells with stem-like properties, but there is also a large body of evidences narrowing down its use as a stem cell marker. In this section of the review we highlight the most relevant issues concerning the role of CD133 as a stem cell marker.

Since the initial discovery in human CD34 positive hematopoietic stem cells $[19,20]$, the expression of CD133 has been found in endothelial progenitors [21], myogenic cells [22], prostatic epithelial stem cells $[23,24]$ and neural stem cells [25-27]. Cells with extensive self-renewal potential and the capacity to engraft, migrate and undergo neural and glial differentiation after orthotopic transplantation in mice were isolated from human fetal brain and post mortem adult brain tissues using FACS sorting with CD133 antibodies. Indeed, evidence for the existence of CD133-expressing cancer stem cell populations (clonogenic expansion in vitro and tumour-initiating capacity in vivo) have been provided in numerous tumour types including leukemia [28], prostate cancer [29], colon cancer [30], lung cancer [31], hepatocellular carcinoma [32], ependymoma [33], melanoma [34], ovarian cancer [35], medulloblastoma and glioblastoma [2,36]. With regard to brain tumours, Singh et al. $[2,36]$ were the first to describe a CD133 positive tumour cell population, with stem cells characteristics that are capable of self-renewal and exact recapitulation of the original tumour when transplanted into immunodeficient mouse brains. They demonstrated that injection of as few as $100 \mathrm{CD} 133$ positive cells produced a tumour whereas injection of 100.000 CD133 negative cells did not.

Quantitative analysis of CD133 positive cells by flow cytometry has generally found them to be present at low and sometimes barely detectable levels in human gliomas, glioma sphere cultures and established glioma cell lines [2,37-40], consistent with the assumption that CSCs are a rare cell population in solid tumours. However, some studies have reported exceptionally high CD133 positive (20\%-60\%) fractions in some human GBMs and/or glioma cell lines [2,38,41], according to immunohistochemical findings demonstrating that many GBMs contain more than 25\% CD133 positive cells [42].

Studies investigating the distribution and the prognostic value of CD133 have reported inconsistent findings [42-49]. On one hand, a quantitative correlation of glioma grade with the presence of CD133 positive cells within tumours and a negative association between CD133 expression and patient survival, have been demonstrated in large cohorts of glioma patients. Opposite results were obtained by Christensen et al. [44] demonstrating no correlation between the presence of tumour cells expressing CD133, and both tumour grade and clinical outcome.

It is noteworthy that CD133 antigen has been used to enrich for cancer stem cells using flow cytometry, but whether CD133 expression measured by mRNA and/or protein on immunoblotting or immunofluoresence identifies cancer stem cells, is not clearly established. However, the association of CD133 mRNA and protein with poor prognosis has been reported in several studies [50-52], including a very recent one that analyses the prognostic impact of CD133 mRNA in 48 glioblastomas [50].

To address the issue of the clinical relevance of CD133, we interrogated the in silico GBM patient databases, REMBRANT and TCGA, and we found that CD133 mRNA does not correlate with patient survival, contrary to what previously shown (Figure 1). This analysis made in hundreds of GBM specimens. is confirming that CD133 has no value as a prognostic marker in glioblastomas.

A great source of inconsistency in experimental results may derive from the use of alternative antibodies recognizing different CD133 protein epitopes. The most widely used antibodies in CD133-related experiments are the $\mathrm{CD} 133 / 1$, directed against the AC133 epitope, and the $\mathrm{CD} 133 / 2$, directed against $\mathrm{AC} 141$ epitope. The $\mathrm{AC} 133$ and $\mathrm{AC} 141$ epitopes are both glycosylated and have distinct spatial locations $[19,20]$, but their molecular nature and their locations on the CD133 protein have not been determined. Several reports have documented overlap of the AC133 and AC141 positive cell populations [19,53,54], although currently there are no specific studies on the comparability of antibodies recognizing these two different epitopes. Indeed, immunohistochemical staining of AC133 and AC141 epitopes poses a special challenge leading some researchers to use alternative antibodies recognizing the CD133 protein. A recent study demonstrated the inconsistent CD133 detection when using different primary CD133 antibody clones in immunohistochemistry $[55,56]$.

In addition, the glycosylated nature of the AC133 epitope has been questioned/discussed since CD133/1antibody can effectively detect bacterially expressed, unglycosylated CD133 [57].

Moreover, the exclusive detection of glycosylation-dependent epitopes does not exclude the expression of differentially or nonglycosylated CD133. Several studies have demonstrated that the AC133 and AC141 epitopes can be downregulated independently on the CD133 mRNA $[53,54]$ and that the tissue distribution of CD133 mRNA is more widespread than expression of the AC133 epitope. CD133 is expressed in differentiated epithelial cells in a variety of tissues, though it has been used to identify normal stem cells and cancer stem cells in many of these organs [58]. 
A

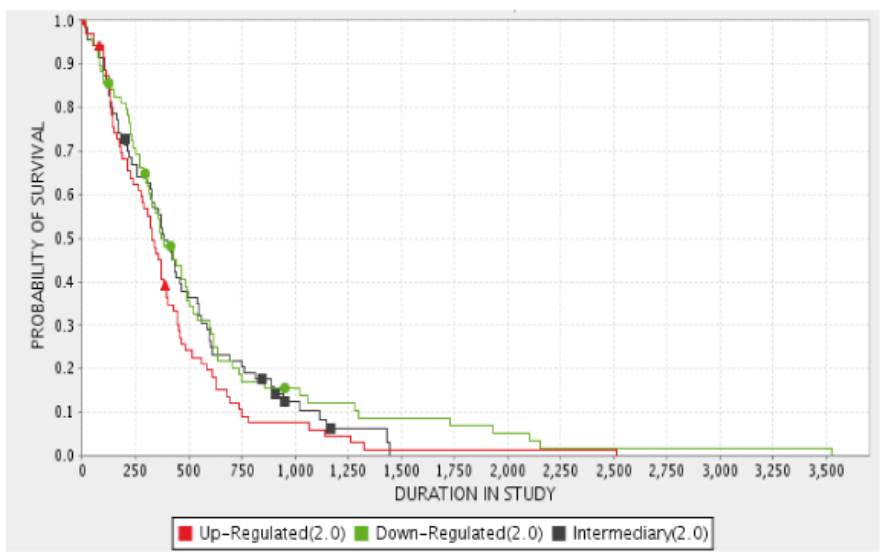

B

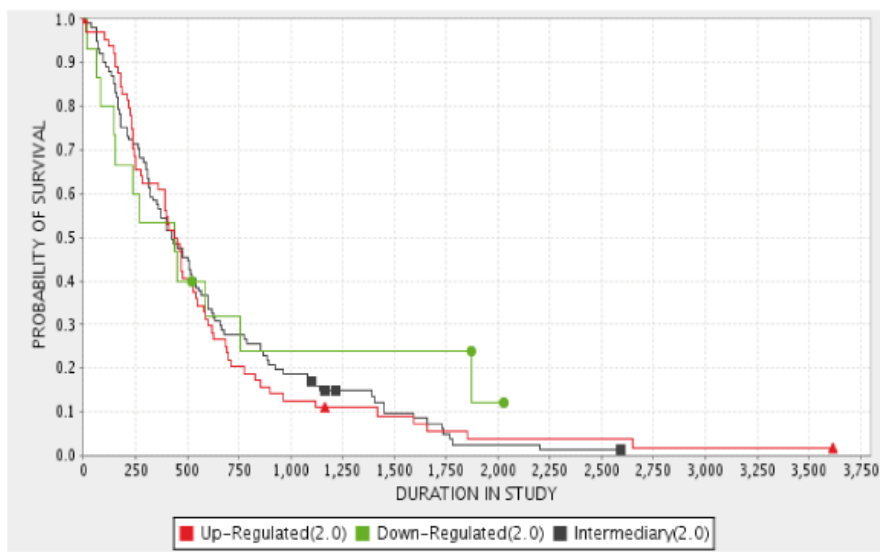

Figure 1: CD133 in GBMs is not predictive of patient survival. Kaplan-Meier survival plot for floiblastoma patients with differential tumor CD133 expression calculated by TGCA (A) and REMBRANT (B) database. The log-rank P-value for significance of difference of survival between group was calculated as $>0.05$ in all cases.

There are several lines of evidence to suggest the existence of CD133 negative glioma stem cells. First, CD133 is not detectable in many fresh GBM specimens $[38,41,59]$ and in established glioma cell lines, which can nonetheless form tumours in vivo [40,41]. Second, cells with stem cell characteristics and tumourigenic potential can be isolated from CD133 negative gliomas as well as from CD133 positive tumours. Stem cells isolated from CD133 positive and negative tumours may differ in terms of other phenotypic features, such as proliferation, invasiveness and expression profiles. A recent study based on gene expression profile analysis of CSC isolated from CD133 positive and CD133 negative gliomas, have led to the definition of two different types of glioma stem cells: Type 1 CSCs that are CD133 positive and grow as floating neurospheres and Type 2 CSCs which are CD133 negative and grow adherently. Interestingly, Type1 cells were reminiscent of fetal neural stem cells and Type 2 cells genetically resemble adult neural stem cells [60]. Third, both CD133 positive and CD133 negative cells isolated from the same tumour specimen can be cultured as neurospheres under serum free conditions, and both population of cells are able to self-renew and to initiate and propagate tumours upon xenotransplantation. Indeed, CD133 negative cells are able to generate CD133 positive progeny in vitro and in vivo [40,61]. Chen et al. [58] recently demonstrated the existence of three different, but coexisting types of glioma stem cells, which differ in CD133 expression: Type 1 (CD133 negative cells able to generate $\mathrm{CD} 133$ positive progeny), Type 2 (CD133 positive cells able to generate CD133 negative cells) and Type 3 (CD133 negative which generate only CD133 negative progeny). A hierarchy lineage has been established between these three types of cells, suggesting that it is a primordial CD133 negative cell that gives rise to $\mathrm{CD} 133$ positive cells in some tumours.

Another important issue that needs to be considered in the criticism of the role of CD133 as marker of stem cells is its still unknown biological function.

\section{Other putative markers of CSCs}

Due in large part to conflicting results and irreproducibility of experiments, a lot of disagreement exists regarding the use of a specific marker or a combination of different markers to identify and isolate GBM CSCs. Besides that, there is an additional complication: as shown by Morrison and colleagues in melanoma [62,63] many markers expressed on CSCs capable of distinguishing marker positive and marker negative populations were also able to regenerate the original expression pattern. The problem of the dynamicity of marker expression oscillating in a cell-cycle dependent manner or becoming re-expressed after purification is remarkable. An emerging complication for the definition of therapeutic-suitable markers is the oscillation between the quiescent and activated states that cells undergo as well as the reversion back to a more primitive state of committed progenitors.

The currently used surface proteins used for identifying CSCs have not been shown to be necessary nor sufficient to confer stem cell-like properties.

\section{L1CAM}

The neuronal cell adhesion molecule L1CAM (L1, CD171) is required for maintaining the growth and survival of $\mathrm{CD} 133$ positive glioma cells with stem-like properties [64].

It has been shown that L1CAM regulates neural cell growth, survival and migration during central nervous system development [65], but its role in the normal adult nervous system is not well defined. In cancers it is over-expressed in gliomas, in which it plays a role in tumour invasion $[66,67]$ and other solid tumours [68-70], including colorectal cancer where L1CAM functions as a prognostic indicator [71].

In gliomas L1CAM positive and CD133 positive cells co-segregate, and levels of L1CAM are higher in glioma cells expressing CD133 than in normal neural progenitors. However, L1CAM has not been used to identify and isolate cancer stem cells. The self-renewal capacity and the tumourigenic potential of L1CAM positive and L1CAM negative subpopulations of glioma cells (even together with CD133) have not been characterized yet.

Targeting L1CAM using lentiviral-mediated short hairpin RNA (shRNA) interference in CD133 positive glioma cells inhibits growth and neurosphere formation of glioma stem cells and induces their apoptosis, by regulating Olig2 expression with associated changes in the downstream effectors, p21WAF1/CIP1 [64]. Indeed, L1CAM mediated signaling confers radioresistance in glioma stem cells by enhancing 
MRN complex function through Myc-NBS1-ATM axis and leading to DNA checkpoint activation and DNA repair [72]. Therefore, L1CAM is an attractive therapeutic target for GBM therapy as it maintains GBM stem cells and regulates their radioresistance.

Furthermore, it has not been determined whether L1CAM itself may have a prognostic value in gliomas andmay be useful in immunohistochemical studies.

\section{CD44}

Several reports have shown the utility of the cell surface marker CD44 in the identification of cancer stem cells in different type of tumours such as breast cancer $[4,73]$, pancreas and prostate carcinomas $[74,75]$. There is only one example of the use of CD44 as a stem cell marker in glioblastoma [76]. Anido et al. show that a CD44high/ Idlhigh cells are localized in the endothelial niches of the tumour tissue and possesses stem cell characteristics. Remarkably, TFG- $\beta$ can regulate this population of cells, causing their depletion and preventing tumour initiation and recurrence. Moreover, it is shown that the high expression levels of both CD44 and Id1 are inversely correlated with survival, conferring poor prognosis in GBM patients.

\section{CD15}

Searching for alternative enrichment markers for stem cells in brain tumours, several groups have identified CD15 as a cell surface protein selectively expressed in cells with tumour initiation capacity. CD15 (also known SSEA-1 [Stage-Specific Embryonic Antigen-1] or $\mathrm{LeX}$ ) is a fructose-containing trisaccharide expressed in adult neural stem/progenitor cells [77] and embryonic stem cells during neural development [78].

It has been demonstrated that in a mouse model of medulloblastoma, the Patched mutant mouse, as well as a subset of human tumours, a distinct subpopulation of cells expressing CD15 is able to propagate tumours. In those tumours CD133 was not found to be expressed exclusively within the stem cell compartment [79]. In human glioblastomas, Son et al. have found that CD15 is an enrichment marker of stem cells in CD133 negative tumours [41]. Approximately $40 \%$ of the freshly isolated GBM specimens that they analyzed do not contain CD133 positive cells. The selection of CD15 positive cells from CD133 negative tumours enriches for cells able to form neurospheres and colonies in soft agar, to differentiate into cells expressing glial and neuronal markers and to be highly tumourigenic in vivo when serially transplanted in immunocompromised mice. Furthermore, a hierarchical lineage has been established between CD15 positive and negative cells, since the CD15 positive cells have the exclusive capacity to generate the cell heterogeneity of the primary tumour.

Even so, as in the case for CD133, CD15 does not enrich for a population of glioblastoma stem cells in every GBM tumour and the levels of CD15 positive cells vary greatly among different brain tumour specimens.

\section{INTEGRIN $\alpha 6$}

Targeting integrin $a 6$ in GBM cells inhibits self-renewal, proliferation, and tumour formation capacity, adding insights to the identification of glioma stem cells. Integrin $a 6$, important for the interaction with lamininexpressing endothelial cells in the microenvironment, is a component of the extracellular matrix whose contact is important for glioma stem cells maintenance. In the brain, laminin and integrin $\alpha 6$ regulate neural stem cell growth [80] and CSC maintenance [81]. The integrin a6-laminin interaction was recently reported to play an important role in the subventricular zone (SVZ) of the lateral ventricles in the adult brain [82]. Biopsy samples from glioblastoma patients showed that integrin $\alpha 6$ positive cells are localized in close proximity to the tumour vasculature and often coexpressed the stem cell markers CD133 and nestin [83]. FACS sorting for integrin a6 alone or in combination with CD133 led to enrichment of cells with higher selfrenewal capacity in vitro. Moreover, combining CD133 and integrin a6 expression resulted in a higher enrichment of glioma stem cells than CD133 expression alone. Xenotransplantation of integrin a6 positive cells in the brains of immunocompromised mice resulted in a higher incidence of secondary tumour formation and a reduced survival than what was obtained with integrin $a 6$ negative cells. Furthermore, integrin a6 depletion using short hairpin RNA or treatment with integrin-blocking antibody reduced both sphere growth in vitro and tumour formation in vivo [83]. In addition to advancing our ability to identify CSCs in gliomas, the findings also point to the potential of targeting integrin $a 6$ for anti-glioblastoma therapy.

\section{The stem cell niche as a potential marker's source}

So far the vast majority of the studies regarding cancer stem cells have focused in the intrinsic properties of these cells, however it is recognized that normal stem cells of various tissues are tightly regulated and sheltered from genotoxic insults, by the microenvironment or stem cell niche. Similarly to normal neural stem cells, the CSCs seems to have potent angiogenic properties and can recruit vessels during tumourigenesis. Moreover, it has been reported that the number of capillaries correlates with the GBM patients' prognosis [84]. Compelling data enhance the idea that a potential marker source may be the stem cell niche: there is, in fact, the possibility to find critical marker components in the cell adhesion molecules since stem cells adherent to the niche are less easily digested during isolation. This idea was born from the initial observation [85] of the preferential distribution of glioma stem cells in the perivascular area (aberrant tumour vasculature). CD133+/Nestin+ cells isolated from glioblastoma, medulloblastoma, ependymomas and oligodendrogliomas migrate to and interact tightly with the vascular tubes formed by endothelial cells.Furthermore, co-transplanting tumour stem cells and endothelial cells into immunocompromised mice, it was shown that endothelialderived factors (such as VEGF) accelerate the initiation and the growth of brain tumours [85]. All these observations are in addition to the fact that the niche has the ability to dedifferentiate non-tumourigenic cells into tumourigenic CSCs [86,87]. This malignant microenvironment might be targeted by anti-angiogenic therapies that would be function via the disruption of stem cell maintenance.

Further insights are provided by the observation that glioblastoma stem-like cell progeny may not be confined to the neural lineage. De Maria's group demonstrated that a proportion of endothelial cells contributing to blood vessels in GBM originates from the tumour itself, directly differentiating from the tumour stem-like cells as a set of endothelial cells lining tumour vessels carry genetic abnormalities found in the tumour cells themselves [7]. Another interesting study [88] showed that the differentiation of tumour stem-like cells into endothelial cells might be mediated initially by the Notch pathway for the differentiation in endothelial progenitor cells and subsequently by the vascular endothelium growth factor (VEGF)-signaling pathway, selectively affecting the differentiation of endothelial progenitors to tumour-derived endothelial cells.

The connection between neural stem cells and the endothelial 
compartment seems to be critical in glioblastoma, where cancer stem cells closely interact with the vascular niche and promote angiogenesis.

\section{Side population}

Some stem cells may additionally express $\mathrm{ABC}$ transporters, responsible for multidrug resistance. ATP binding (ABC) cassette transporters, able to pump the fluorescent dye HOECHST-33342 out of the cell [89], identify unlabelled "side-population" (SP) highly enriched in stem cells in many tissues, including neural $[90,91]$. The capacity to eject the dye HOECHST-33342 is based on ABCG2 expression, a multidrug resistance protein that is expressed in stem cells but not in downstream progenitors, and thus defines a SP population highly enriched in stem cells in various tissues [92]. A growing body of evidence suggests that GBM and gliomas in general arise from the "side-population" subset of cells. The SP fraction isolated from the C6 glioma cell line exhibited the stem cell properties of selfrenewal and multipotency and could re-form more differentiated SPnegative cells characteristic of the original cell line. These SP-positive cells were also tumourigenic in vivo, whereas SP-negative cells were not [93]. In a mouse model of glioma, it has been demonstrated that CSCs are enriched in the SP [94]. This cell fraction isolated from different primary tumour cells is able to substain expansion ex-vivo and to generate SP and non-SP progeny [95]. The SP isolated from brain tumours is capable of neurospheres formation with self-renewal and differentiation potential, is chemo-resistant and expresses high levels of drug-transporters proteins such as MDR-1, MRP-1, ABCG2 [96]. However, there are conflicting data showing that either the sorted SP or non-SP cells were similarly clonogenic in vitro and equally tumourigenic in vivo. In addition, when culturing SP and non-SP cells it has been demonstrated in gastrointestinal cancer cell lines that the two populations are inter-convertible, each giving rise to the other [97], even though they represent phenotypically different populations.

Several questions need to be answered regarding the role of ABCG2 in glioma biology. The Holland group has shed light on the ABCG2 activity and the resulting SP phenotype showing that ABCG2 function and localization to the plasma membrane are regulated by the PI3K and Akt pathways. Moreover, ABC transporter's function is lost in glioma endothelial cells, correlating with the blood brain barrier loss of integrity seen in glioma patients [98].

The same group previously investigated the role of nitric oxide (NO) activity in the perivascular niche using a mouse genetic model of PDGF-induced gliomas [99] and found that eNOS (endothelial nitric oxide synthase) expression is elevated in the tumour vasculature adjacent to the glioma cells and the Notch signalling driven by $\mathrm{NO} /$ cGMP pathway induces the SP phenotype in primary glioma cell cultures. The production of nitric oxide was shown to increase neurosphere forming capacity and the in vivo tumourigenic capacity of PDGF-driven glioma primary cultures, while its suppression prolongs mice survival. Even if the contribution of aberrant NO signaling within the niche is obviously not the only contribution to gliomagenesis, its role in tumour angiogenesis and the involvement of the perivascular niche in the disease process, it's worthy of further investigation as a potential therapeutic target.

\section{High ALDH activity as a functional marker to isolate CSCs}

A complementary strategy for the functional identification of normal stem cells and their malignant counterparts involves the measurement of aldehyde dehydrogenase (ALDH) activity. Aldehyde dehydrogenases (ALDH) are a family of enzymes that efficiently detoxify aldehydic products generated by reactive oxygen species and might therefore participate in cell survival. ALDH enzymes activity is important for drug resistance, cell proliferation, differentiation, and the response to oxidative stress [100-102]. High ALDH activity has been used to identify and select stem-like subsets in hematopoietic cells [103], endothelial progenitor cells, and mesenchymal and epithelial stem cells [104-106]. It is becoming increasingly clear that ALDH activity can be used, either alone or in combination with cell surface markers, to identify CSCs in hematologic malignancies and various solid carcinomas such as colon, breast and lung [100,101,107,108]. A group of investigators adopted the complex fluorescence-activated cell sorting based on high ALDH enzyme activity to select tumour initiating cells, which correlates with enhanced clonogenicity and invasiveness in vitro $[109,110]$. This isolation approach might present advantages: whilst the surface phenotype of a stem cell may remain stable over time, the functional activity may decline.

Moreover, it has been shown that ALDH1 inhibition induces differentiation in vitro and reduces clonogenicity [111]. Consequently, ALDH1 activity might be a functional correlate of an undifferentiated state of glioma cells capable of growing in neurospheres, and appears to confer specific advantage to stem cells despite the fact that the molecular nature of this advantage is not yet clear. Therefore, detection of ALDH activity as a purification strategy might render the identification more reliable and with a high level of experimental reproducibility. Cell migration ability as potential CSCs isolation method. We should also consider the hypothesis [112] to isolate and enrich cancer stem cell based on the heterogeneity of invasiveness of tumoural cells, according to the findings that the CSCs possess more infiltrative capability than their progeny [113].

\section{Dye-based marker-independent method to segregate CSCs}

An alternative approach to investigate tumour-initiating potential in gliomas exploits intrinsic autofluorescence properties and distinctive morphology of human glioma cells [114]. This method can discern a subpopulation of human cells displaying autofluorescence around $520 \mathrm{~nm}$ upon laser excitation at $488 \mathrm{~nm}$. Moreover, the same fraction retains spherogenic potential for at least 5 passages (yielding spheres with bigger size) while nonfluorescent cells lose their clonogenic capacity between passage 3 and 4 . In addition to their enhanced selfrenewal and multipotency, these auto-fluorescent cells also are highly tumourigenic as injection of as few as 3000 cells per mouse consistently yielded tumours. The molecular basis of this autofluorescence is unknown but it probably reflects higher metabolic and proliferative activity.

The identification of a dye-retaining brain tumour population enables the identification of a subpopulation displaying the hallmarks of a tumour-initiating sub-population. Several groups have recently shown that the isolation of a label-retaining cell fraction bearing robustly identifies cancer stem cells from solid tumours such as breast [115], skin [63], and pancreatic [116] cancers. To determine if such population exists in GBM as well, the Vescovi and Reynolds' groups [117] exploited the properties of CFSE (the prodrug carboxyfluorescein diacetate succinimidylester), which is converted by cellular esterase activity into a fluorescent compound covalently bound to proteins and retained within the cells. Since the dye is equally divided between daughter cells after division, it is possible to follow label retention and the decreasing fluorescence intensity with time. The authors observed that bright cells dilute the dye significantly slower than the overall population, exhibiting a lower frequency of cell division, and that 
Citation: Brescia P, Richichi C, Pelicci G (2011) Identification of Glioma Stem Cells: What is Already Known and How Far do We Still Need to Go? The Biomarkers Dilemma. J Carcinogene Mutagene S1:003. doi:10.4172/2157-2518.S1-003

these cells constitute a label-retaining population of glioma-initiating cells. Moreover, this cell fraction carries a greater tumourinitiation ability in vivo and displays migratory and infiltration capability. These observations are in agreement with the hypothesis that cancer stem cells are a slow-cycling, infrequent population endowed with the selfrenewal and multipotent differentiation features of a stem cell.

\section{Conclusion}

These results support the phenotypic diversity of tumour cells and the cellular phenotype strongly correlated with stemness and tumourigenic capacity. It is conceivable that subpopulations grouped by markers expression such as CD133, CD15, L1CAM, or integrin a6 for instance, represent distinct functional entities that contribute to the phenotypes of human GBMs which thus far cannot be encompassed by a single CSC marker. Considering the inconsistency between stem cell markers, there is a need to define CSCs using more precise functional markers, for example by receptors for growth or chemotactic factors involved in stem cells maintenance or differentiation.

Thus, the heterogeneity observed in brain tumours may be correlated to the diversity on a cellular level, in which different subpopulations of glioma cells are dedicated towards different functional roles. Given the complex genetic and epigenetic heterogeneity of GBMs, it is unlikely that the expression of a single marker will define CSCs in every tumours, hence a combination of markers will probably best define glioma tumour stem cells. Furthermore the ability to molecularly determine this characteristic may permit the development of more tailored brain cancers treatment.

Although several markers show promises and good potential in early studies, the lack of reliable data (caused by a lack of standardized approaches regarding methods for GBM-derived cells isolation and the procedure adopted for defining 'stemness') makes their clinical value difficult to determine.

\section{Acknowledgements}

The authors wish to thank Paul Massa for manuscript editing. GP was supported by AICR and AIRC grants. PB was supported by Umberto Veronesi Foundation (FUV).

\section{References}

1. Galli R, Binda E, Orfanelli U, Cipelletti B, Gritti A, et al. (2004) Isolation and characterization of tumourigenic, stem-like neural precursors from human glioblastoma. Cancer Res 64: 7011-7021.

2. Singh SK, Hawkins C, Clarke ID, Squire JA, Bayani J, et al. (2004) Identification of human brain tumour initiating cells. Nature 432: 396-401.

3. Bao S, Wu Q, McLendon RE, Hao Y, Shi Q, et al. (2006) Glioma stem cells promote radioresistance by preferential activation of the DNA damage response. Nature 444: 756-760.

4. Al-Hajj M, Wicha MS, Benito-Hernandez A, Morrison SJ, Clarke MF (2003) Prospective identification of tumourigenic breast cancer cells. Proc Natl Acad Sci U S A 100: 3983-3988.

5. Kelly K, Yin JJ (2008) Prostate cancer and metastasis initiating stem cells. Cell Res 18: 528-537.

6. Lee CJ, Dosch J, Simeone DM (2008) Pancreatic cancer stem cells. J Clin Oncol 26: 2806-2812.

7. Ricci-Vitiani L, Lombardi DG, Pilozzi E, Biffoni M, Todaro M, et al. (2007) Identification and expansion of human colon-cancer-initiating cells. Nature 445: $111-115$

8. Quintana E, Shackleton M, Sabel MS, Fullen DR, Johnson TM, et al. (2008)
Efficient tumour formation by single human melanoma cells. Nature 456: 593598.

9. Baum CM, Weissman IL, Tsukamoto AS, Buckle AM, Peault B (1992) Isolation of a candidate human hematopoietic stem-cell population. Proc Natl Acad Sci U S A 89: 2804-2808.

10. Reya T, Morrison SJ, Clarke MF, Weissman IL (2001) Stem cells, cancer, and cancer stem cells. Nature 414: 105-111.

11. Cl Clarke MF, Dick JE, Dirks PB, Eaves CJ, Jamieson CH, et al. (2006) Cancer stem cells--perspectives on current status and future directions: AACR Workshop on cancer stem cells. Cancer Res 66: 9339-9344.

12. Dick JE (2008) Stem cell concepts renew cancer research. Blood 1124793 4807.

13. Pollard SM, Conti L, Sun Y, Goffredo D, Smith A (2006) Adherent neural stem (NS) cells from fetal and adult forebrain. Cereb Cortex 1: 112-120.

14. Sun Y, Pollard S, Conti L, Toselli M, Biella G, et al. (2008) Long-term tripotent differentiation capacity of human neural stem (NS) cells in adherent culture. Mol Cell Neurosci 38: 245-258.

15. Reynolds BA, Tetzlaff W, Weiss S (1992) A multipotent EGF-responsive striata embryonic progenitor cell produces neurons and astrocytes. J Neurosci 12: 4565-4574.

16. Reynolds BA, Weiss S (1992) Generation of neurons and astrocytes from isolated cells of the adult mammalian central nervous system. Science 255 : 1707-1710.

17. Lee J, Kotliarova S, Kotliarov Y, Li A, Su Q, et al. (2006) Tumour stem cells derived from glioblastomas cultured in bFGF and EGF more closely mirror the phenotype and genotype of primary tumours than do serum-cultured cell lines. Cancer Cell 9: 391-403.

18. Laks DR, Masterman-Smith M, Visnyei K, Angenieux B, Orozco NM, et al (2009) Neurosphere formation is an independent predictor of clinical outcome in malignant glioma. Stem Cells 27: 980-987.

19. Yin AH, Miraglia S, Zanjani ED, Almeida-Porada G, Ogawa M, et al. (1997) AC133, a novel marker for human hematopoietic stem and progenitor cells. Blood 90: 5002-5012.

20. Miraglia S, Godfrey W, Yin AH, Atkins K, Warnke R, et al. (1997) A novel five transmembrane hematopoietic stem cell antigen: isolation, characterization, and molecular cloning. Blood 90: 5013-5021.

21. Miraglia S, Godfrey W, Yin AH, Atkins K, Warnke R, et al. (2000) Expression of VEGFR-2 and AC133 by circulating human CD34(+) cells identifies a population of functional endothelial precursors. Blood: 95: 952-958.

22. Torrente $Y$, Belicchi M, Sampaolesi M, Pisati F, Meregalli M, et al. (2004) Human circulating AC133(+) stem cells restore dystrophin expression and ameliorate function in dystrophic skeletal muscle. J Clin Invest 114: 182-195.

23. Richardson GD, Robson CN, Lang SH, Neal DE, Maitland NJ, et al. (2004) CD133, a novel marker for human prostatic epithelial stem cells. J Cell Sci 117 3539-3545.

24. Leong KG, Wang BE, Johnson L, Gao WQ (2008) Generation of a prostate from a single adult stem cell. Nature 456: 804-808.

25. Uchida N, Buck DW, He D, Reitsma MJ, Masek M, et al. (2000) Direct isolation of human central nervous system stem cells. Proc Natl Acad Sci U S A 97 14720-14725.

26. Tamaki S, Eckert K, He D, Sutton R, Doshe M, et al. (2002) Engraftment of sorted/expanded human central nervous system stem cells from fetal brain. $J$ Neurosci Res 69: 976-986.

27. Schwartz PH, Bryant PJ, Fuja TJ, Su H, O'Dowd DK (2003) Isolation and characterization of neural progenitor cells from post-mortem human cortex. J Neurosci Res 74: 838-851.

28. Bhatia M (2001) AC133 expression in human stem cells. Leukemia 15: 1685 1688.

29. Collins AT, Berry PA, Hyde C, Stower MJ, Maitland NJ (2005) Prospective 
Citation: Brescia P, Richichi C, Pelicci G (2011) Identification of Glioma Stem Cells: What is Already Known and How Far do We Still Need to Go? The Biomarkers Dilemma. J Carcinogene Mutagene S1:003. doi:10.4172/2157-2518.S1-003

identification of tumourigenic prostate cancer stem cells. Cancer Res 65: 10946-10951.

30. O'Brien CA, Pollett A, Gallinger S, Dick JE (2007) A human colon cancer cell capable of initiating tumour growth in immunodeficient mice. Nature 445: 106110.

31. Eramo A, Lotti F, Sette G, Pilozzi E, Biffoni M, et al. (2008) Identification and expansion of the tumourigenic lung cancer stem cell population. Cell Death Differ 15: 504-514

32. Suetsugu A, Nagaki M, Aoki H, Motohashi T, Kunisada T, et al. (2006) Characterization of CD133+ hepatocellular carcinoma cells as cancer stem/ progenitor cells. Biochem Biophys Res Commun 351: 820-824.

33. Taylor MD, Poppleton H, Fuller C, Su X, Liu Y, et al. (2005) Radial glia cells are candidate stem cells of ependymoma. Cancer Cell 8: 323-335.

34. Monzani E, Facchetti F, Galmozzi E, Corsini E, Benetti A, et al. (2007) Melanoma contains $\mathrm{CD} 133$ and $\mathrm{ABCG} 2$ positive cells with enhanced tumourigenic potential. Eur J Cancer 43: 935-46.

35. Ferrandina G, Bonanno G, Pierelli L, Perillo A, Procoli A, et al. (2008) Expression of CD133-1and CD133-2 in ovarian cancer. Int J Gynecol Cancer 18: $506-514$

36. Singh SK, Clarke ID, Terasaki M, Bonn VE, Hawkins C, et al. (2003) Identification of a cancer stem cell in human brain tumours. Cancer Res 63 : 5821-5828.

37. Clément V, Dutoit V, Marino D, Dietrich PY, Radovanovic I et al. (2009) Limits of CD133 as a marker of glioma self-renewing cells. Int J Cancer 125: 244-248.

38. Joo KM, Kim SY, Jin X, Song SY, Kong DS, et al. (2008) Clinical and biological implications of CD133-positive and CD133-negative cells in glioblastomas. Lab Invest 88: 808-815.

39. Shu Q, Wong KK, Su JM, Adesina AM, Yu LT, et al. (2008) Direct orthotopic transplantation of fresh surgical specimen preserves CD133+ tumour cells in clinically relevant mouse models of medulloblastoma and glioma. Stem Cells 26: $1414-1424$

40. Wang J, Sakariassen PØ, Tsinkalovsky O, Immervoll H, Bøe SO, et al. (2008) CD133 negative glioma cells form tumours in nude rats and give rise to CD133 positive cells. Int J Cancer 122: 761-768

41. Son MJ, Woolard K, Nam DH, Lee J, Fine HA (2009) SSEA-1 is an enrichment marker for tumour-initiating cells in human glioblastoma. Cell Stem Cell 4: 440452

42. Zeppernick F, Ahmadi R, Campos B, Dictus C, Helmke BM, et al. (2008) Stem cell marker CD133 affects clinical outcome in glioma patients. Clin Cancer Res 14: 123-129

43. Beier D, Wischhusen J, Dietmaier W, Hau P, Proescholdt M, et al. (2008) CD133 expression and cancer stem cells predict prognosis in high-grade oligodendroglial tumours. Brain Pathol 18: 370-377.

44. Christensen K, Schrøder HD, Kristensen BW (2008) CD133 identifies perivascular niches in grade II-IV astrocytomas. J Neurooncol 90: 157-70.

45. Immervoll H, Hoem D, Sakariassen PØ, Steffensen OJ, Molven A (2008) Expression of the "stem cell marker" CD133 in pancreas and pancreatic ducta adenocarcinomas. BMC Cancer 8: 48 .

46. Pallini R, Ricci-Vitiani L, Banna GL, Signore M, Lombardi D, et al. (2008) Cancer stem cell analysis and clinical outcome in patients with glioblastoma multiforme. Clin Cancer Res 14: 8205-8212.

47. Rebetz J, Tian D, Persson A, Widegren B, Salford LG, et al. (2008) Glia progenitor-like phenotype in low-grade glioma and enhanced CD133expression and neuronal lineage differentiation potential in high-grade glioma. PLoS One 3: e1936.

48. Thon N, Damianoff K, Hegermann J, Grau S, Krebs B, et al. (2010) Presence of pluripotent CD133+ cells correlates with malignancy of gliomas. Mol Cell Neurosci 43: 51-59.

49. Zhang M, Song T, Yang L, Chen R, Wu L, et al. (2008) Nestin and CD133: valuable stem cellspecific markers for determining clinical outcome of glioma patients. J Exp Clin Cancer Res 27: 85.
50. Metellus P, Nanni-Metellus I, Delfino C, Colin C, Tchogandjian A, et al. (2011) Prognostic Impact of CD133 mRNA Expression in 48 Glioblastoma Patients Treated with Concomitant Radiochemotherapy: a Prospective Patient Cohort at a Single Institution. Ann Surg Oncol 18: 2937-2945.

51. Raso A, Mascelli S, Biassoni R, Nozza P, Kool M, et al. (2011) High levels of PROM1 (CD133) transcript are a potential predictor of poor prognosis in medulloblastoma. Neuro Oncol 13: 500-508.

52. Yu JW, Zhang P, Wu JG, Wu SH, Li XQ, et al. (2010) Expressions and clinical significances of CD133 protein and CD133 mRNA in primary lesion of gastric adenocacinoma. J Exp Clin Cancer Res 29: 141

53. Corbeil D, Röper K, Hellwig A, Tavian M, Miraglia S, et al. (2000) The human AC133 hematopoietic stem cell antigen is also expressed in epithelial cells and targeted to plasma membrane protrusions. J Biol Chem 275: 5512-55120.

54. Florek M, Haase M, Marzesco AM, Freund D, Ehninger G, et al. (2005) Prominin-1/CD133, a neural and hematopoietic stem cell marker, is expressed in adult human differentiated cells and certain types of kidney cancer. Cell Tissue Res 319: 15-26.

55. Bidlingmaier S, Zhu X, Liu B (2008) The utility and limitations of glycosylated human CD133 epitopes in defining cancer stem cells. J Mol Med 86: 10251032.

56. Hermansen SK, Christensen KG, Jensen SS, Kristensen BW (2011) Inconsistent immunohistochemical expression patterns of four different CD133 antibody clones in glioblastoma. J Histochem Cytochem 59: 391-407.

57. Kemper K, Sprick MR, de Bree M, Scopelliti A, Vermeulen L, et al. (2010) The AC133 epitope, but not the CD133 protein, is lost upon cancer stem cell differentiation. Cancer Res 70: 719-29.

58. Shmelkov SV, Butler JM, Hooper AT, Hormigo A, Kushner J, et al. (2008) CD133 expression is not restricted to stem cells, and both CD133+ and CD133metastatic colon cancer cells initiate tumours. J Clin Invest 118: 2111-2120.

59. Beier D, Hau P, Proescholdt M, Lohmeier A, Wischhusen J, et al. (2007) CD133(+) and CD133(-) glioblastoma-derived cancer stem cells show differential growth characteristics and molecular profiles. Cancer Res 67: 40104015.

60. Lottaz C, Beier D, Meyer K, Kumar P, Hermann A, et al. (2010) Transcriptiona profiles of CD133+ and CD133- glioblastoma-derived cancer stem cell lines suggest different cells of origin. Cancer Res 70: 2030-2040.

61. Chen R, Nishimura MC, Bumbaca SM, Kharbanda S, Forrest WF, et al. (2010) A hierarchy of self-renewing tumour-initiating cell types in glioblastoma. Cancer Cell 17: 362-375.

62. Quintana E, Shackleton M, Foster HR, Fullen DR, Sabel MS, et al. (2010) Phenotypic heterogeneity among tumourigenic melanoma cells from patients that is reversible and not hierarchically organized. Cancer Cell 18: 510-5123.

63. Roesch A, Fukunaga-Kalabis M, Schmidt EC, Zabierowski SE, Brafford PA, et al. (2010) A temporarily distinct subpopulation of slow-cycling melanoma cells is required for continuous tumour growth. Cell 14: 583-594.

64. Bao S, Wu Q, Li Z, Sathornsumetee S, Wang H, et al. (2008) Targeting cance stem cells through L1CAM suppresses glioma growth. Cancer Res 68: 60436048 .

65. Maness PF, Schachner M (2007) Neural recognition molecules of the immunoglobulin superfamily: signaling transducers of axon guidance and neuronal migration. Nat Neurosci 10: 19-26.

66. Izumoto S, Ohnishi T, Arita N, Hiraga S, Taki T, et al. (1996) Gene expression of neural cell adhesion molecule L1 in malignant gliomas and biologica significance of L1 in glioma invasion. Cancer Res 56: 1440-1444

67. Suzuki T, Izumoto S, Fujimoto Y, Maruno M, Ito Y, et al. (2005) Clinicopathologica study of cellular proliferation and invasion in gliomatosis cerebri: important role of neural cell adhesion molecule L1 in tumour invasion. J Clin Pathol 58: 166 171.

68. Arlt MJ, Novak-Hofer I, Gast D, Gschwend V, Moldenhauer G, et al. (2006) Efficient inhibition of intra-peritoneal tumour growth and dissemination of human ovarian carcinoma cells in nude mice by anti-L1-cell adhesion molecule monoclonal antibody treatment. Cancer Res 66: 936-943. 
Citation: Brescia P, Richichi C, Pelicci G (2011) Identification of Glioma Stem Cells: What is Already Known and How Far do We Still Need to Go? The Biomarkers Dilemma. J Carcinogene Mutagene S1:003. doi:10.4172/2157-2518.S1-003

Page 8 of 9

69. Thies A, Schachner M, Moll I, Berger J, Schulze HJ, et al. (2002) Overexpression of the cell adhesion molecule L1 is associated with metastasis in cutaneous malignant melanoma. Eur J Cancer 38: 1708-1716.

70. Allory Y, Matsuoka Y, Bazille C, Christensen El, Ronco P, et al. (2005) The $\mathrm{L} 1$ cell adhesion molecule is induced in renal cancer cells and correlates with metastasis in clear cell carcinomas. Clin Cancer Res 11: 1190-1197.

71. Boo YJ, Park JM, Kim J, Chae YS, Min BW, et al. (2007) L1 expression as a marker for poor prognosis, tumour progression, and short survival in patients with colorectal cancer. Ann Surg Oncol 14: 1703-1711.

72. Cheng L, Wu Q, Huang Z, Guryanova OA, Huang Q, et al. (2011) L1CAM regulates DNA damage checkpoint response of glioblastoma stem cells through NBS1. EMBO J 30: 800-813.

73. Yu, F., Yao, H., Zhu, P., Zhang, X., Pan, Q. et al. (2007) let-7 regulates self renewal and tumourigenicity of breast cancer cells. Cell 131: 1109-23.

74. Li C, Heidt DG, Dalerba P, Burant CF, Zhang L, et al. (2007) Identification of pancreatic cancer stem cells. Cancer Res 67: 1030-1037.

75. Patrawala L, Calhoun T, Schneider-Broussard R, Li H, Bhatia B, et al. (2006) Highly purified CD44+ prostate cancer cells from xenograft human tumours are enriched in tumourigenic and metastatic progenitor cells. Oncogene 25: 1696708 .

76. Anido J, Sáez-Borderías A, Gonzàlez-Juncà A, Rodón L, Folch G, et al. (2010) TGF-beta Receptor Inhibitors Target the CD44(high)/ld1(high) Glioma-Initiating Cell Population in Human Glioblastoma. Cancer Cell 18: 655-668.

77. Capela A, Temple S (2002) LeX/ssea- 1 is expressed by adult mouse CNS stem cells, identifying them as nonependymal. Neuron 35 : 865-875.

78. Capela A, Temple S (2006) LeX is expressed by principle progenitor cells in the embryonic nervous system, is secreted into their environment and binds Wnt-1. Dev Biol 291: 300-313.

79. Read TA, Fogarty MP, Markant SL, McLendon RE, Wei Z, et al. (2009) Identification of CD15 as a marker for tumour-propagating cells in a mouse model of medulloblastoma. Cancer Cell 15: 135-147.

80. Hall PE, Lathia JD, Caldwell MA, Ffrench-Constant C (2008) Laminin enhances the growth of human neural stem cells in defined culture media. BMC Neurosci 9: 71.

81. Fael Al-Mayhani TM, Ball SL, Zhao JW, Fawcett J, Ichimura K, et al. (2009) An efficient method for derivation and propagation of glioblastoma cell lines that conserves the molecular profile of their original tumours. J Neurosci Methods 176:192-199.

82. Shen Q, Wang Y, Kokovay E, Lin G, Chuang SM, et al. (2008) Adult SVZ stem cells lie in a vascular niche: a quantitative analysis of niche cell-cell interactions. Cell Stem Cell 3: 289-300.

83. Lathia JD, Gallagher J, Heddleston JM, Wang J, Eyler CE, et al. (2010) Integrin alpha 6 regulates glioblastoma stem cells. Cell Stem Cell 6: 421-432.

84. Leon SP, Folkerth RD, Black PM (1996) Microvessel density is a prognostic indicator for patients with astroglial brain tumours. Cancer 77: 362-372.

85. Calabrese C, Poppleton H, Kocak M, Hogg TL, Fuller C, et al. (2007) A perivascular niche for brain tumour stem cells. Cancer Cell 11: 69-82.

86. Li Z, Bao S, Wu Q, Wang H, Eyler C, et al. (2009) Hypoxia-inducible factors regulate tumourigenic capacity of glioma stem cells. Cancer Cell 15: 501-13.

87. Heddleston JM, Li Z, McLendon RE, Hjelmeland AB, Rich JN (2009) The hypoxic microenvironment maintains glioblastoma stem cells and promotes reprogramming towards a cancer stem cell phenotype. Cell Cycle 8: 32743284.

88. Wang R, Chadalavada K, Wilshire J, Kowalik U, Hovinga KE, et al. (2010) Glioblastoma stem-like cells give rise to tumour endothelium. Nature 468: 829833.

89. Goodell MA, Brose K, Paradis G, Conner AS, Mulligan RC (1996) Isolation and functional properties of murine hematopoietic stem cells that are replicating in vivo. J Exp Med 183: 1797-1806.

90. Kim M, Morshead CM (2003) Distinct populations of forebrain neural stem and progenitor cells can be isolated using side-population analysis. J Neurosci 23 10703-10709.

91. Wu C, Alman BA (2008) Side population cells in human cancers. Cancer Lett 268: $1-9$

92. Challen GA, Little MH (2006) A side order of stem cells: the SP phenotype. Stem Cells 24: 3-12.

93. Kondo T, Setoguchi T, Taga T (2004) Persistence of a small subpopulation of cancer stemlike cells in the C6 glioma cell line. Proc Natl Acad Sci U S A 101 781-786.

94. Harris MA, Yang H, Low BE, Mukherjee J, Guha A, et al. (2008) Cancer stem cells are enriched in the side population cells in a mouse model of glioma. Cancer Res 68: 10051-10059.

95. Hirschmann-Jax C, Foster AE, Wulf GG, Nuchtern JG, Jax TW, et al. (2004) A distinct "side population" of cells with high drug efflux capacity in human tumour cells. Proc Natl Acad Sci U S A 101: 14228-14233.

96. Patrawala L, Calhoun T, Schneider-Broussard R, Zhou J, Claypool K, et al (2005) Side population is enriched in tumourigenic, stem-like cancer cells, whereas ABCG2+ and ABCG2- cancer cells are similarly tumourigenic. Cancer Res 65: 6207-6219.

97. Burkert J, Otto WR, Wright NA (2008) Side populations of gastrointestina cancers are not enriched in stem cells. J Pathol 214: 564-573.

98. Bleau AM, Hambardzumyan D, Ozawa T, Fomchenko El, Huse JT, et al. (2009) PTEN/PI3K/Akt pathway regulates the side population phenotype and ABCG2 activity in glioma tumour stem-like cells. Cell Stem Cell 4: 226-235.

99. Charles N, Ozawa T, Squatrito M, Bleau AM, Brennan CW, et al. (2010) Perivascular nitric oxide activates notch signaling and promotes stem-like character in PDGF-induced glioma cells. Cell Stem Cell 6: 141-152.

100. Huang EH, Hynes MJ, Zhang T, Ginestier C, Dontu G, et al. (2009) Aldehyde dehydrogenase 1 is a marker for normal and malignant human colonic stem cells (SC) and tracks SC overpopulation during colon tumourigenesis. Cancer Res 69: 3382-3389.

101. Ginestier C, Hur MH, Charafe-Jauffret E, Monville F, Dutcher J, et al. (2007) ALDH1 is a marker of normal and malignant human mammary stem cells and a predictor of poor clinical outcome. Cell Stem Cell 1: 555-567.

102.Douville J, Beaulieu R, Balicki D (2009) ALDH1 as a functional marker of cancer stem and progenitor cells. Stem Cells Dev 18: 17-25.

103. Storms RW, Trujillo AP, Springer JB, Shah L, Colvin OM, et al. (1999) Isolation of primitive human hematopoietic progenitors on the basis of aldehyde dehydrogenase activity. Proc Natl Acad Sci U S A 96: 9118-9123.

104.Gentry T, Foster S, Winstead L, Deibert E, Fiordalisi M, et al. (2007) Simultaneous isolation of human BM hematopoietic, endothelial and mesenchymal progenitor cells by flow sorting based on aldehyde dehydrogenase activity: implications for cell therapy. Cytotherapy 9: 259-74.

105.Povsic TJ, Zavodni KL, Kelly FL, Zhu S, Goldschmidt-Clermont PJ, et al. (2007) Circulating progenitor cells can be reliably identified on the basis of aldehyde dehydrogenase activity. J Am Coll Cardiol 50: 2243-2248.

106. Matsui W, Huff CA, Wang Q, Malehorn MT, Barber J, et al. (2004) Characterization of clonogenic multiple myeloma cells. Blood 103: 2332-2336.

107.Pearce DJ, Taussig D, Simpson C, Allen K, Rohatiner AZ, et al. (2005) Characterization of cells with a high aldehyde dehydrogenase activity from cord blood and acute myeloid leukemia samples. Stem Cells 23: 752-760.

108. Ucar D, Cogle CR, Zucali JR, Ostmark B, Scott EW, et al. (2009) Aldehyde dehydrogenase activity as a functional marker for lung cancer. Chem Biol Interact 178: 48-55

109. Corti S, Locatelli F, Papadimitriou D, Donadoni C, Salani S, et al. (2006) Identification of a primitive brain-derived neural stem cell population based on aldehyde dehydrogenase activity. Stem Cells 24: 975-985.

110.van den Hoogen C, van der Horst G, Cheung H, Buijs JT, Lippitt JM, et al (2010) High aldehyde dehydrogenase activity identifies tumour-initiating and 
Citation: Brescia P, Richichi C, Pelicci G (2011) Identification of Glioma Stem Cells: What is Already Known and How Far do We Still Need to Go? The Biomarkers Dilemma. J Carcinogene Mutagene S1:003. doi:10.4172/2157-2518.S1-003

metastasisinitiating cells in human prostate cancer. Cancer Res 70: 51635173.

111. Rasper M, Schäfer A, Piontek G, Teufel J, Brockhoff G, et al. (2010) Aldehyde dehydrogenase 1 positive glioblastoma cells show brain tumour stem cell capacity. Neuro Oncol 12: 1024-1033.

112. Yu SC, Bian XW (2009) Enrichment of cancer stem cells based on heterogeneity of invasiveness. Stem Cell Rev 5: 66-71.

113. Tamase A, Muraguchi T, Naka K, Tanaka S, Kinoshita M, et al. (2009) Identification of tumourinitiating cells in a highly aggressive brain tumour using promoter activity of nucleostemin. Proc Natl Acad Sci U S A 106: 1716317168.
114. Clément V, Marino D, Cudalbu C, Hamou MF, Mlynarik V, et al. (2010) Markerindependent identification of glioma-initiating cells. Nat Methods 7: 224-228.

115. Pece S, Tosoni D, Confalonieri S, Mazzarol G, Vecchi M, et al. (2010) Biological and molecular heterogeneity of breast cancers correlates with their cancer stem cell content. Cell 140: 62-73.

116. Dembinski JL, Krauss S (2009) Characterization and functional analysis of a slow cycling stem cell-like subpopulation in pancreas adenocarcinoma. Clin Exp Metastasis 26: 611-23.

117. Deleyrolle LP, Harding A, Cato K, Siebzehnrubl FA, Rahman M, et al. (2011) Evidence for label-retaining tumour-initiating cells in human glioblastoma. Brain 134: 1331-43
This article was originally published in a special issue, Stem Cells-Cancer Research handled by Editor(s). Dr. Claudio Luparello, University of Palermo, Italy 